\title{
Study on Microstructure and mechanical properties of Cold Spraying Al coating on Magnesium Alloy
}

\author{
Yuliang LIU ${ }^{1,2}$ a, Xiangli Li ${ }^{3}$, Qing ZHANG ${ }^{1,2}$ Chunhua $X u^{1,2}$ \\ ${ }^{1}$ School of Materials Science and Engineering, Henan University of Science and Technology, \\ Luoyang, China \\ ${ }^{2}$ Collaborative Innovation Center of Nonferrous Metals, Henan Province, Luoyang, China \\ ${ }^{3}$ Technology \& Economy of Xuchang School, Xuchang, China \\ apurelandliu@126.com
}

Keywords: Cold spraying, Al coating, Magnesium alloy, Microstructure

\begin{abstract}
Al coating is formed on AZ31 magnesium alloy by Cold spraying. plane and cross-sectional microstructure of cold spraying $\mathrm{Al}$ coating are investigated. The results show that $\mathrm{Al}$ particles are deformed significantly compared with original particles and $\mathrm{Al}$ coating is well bonded with the substrate. The microhardness of Al coating is about $178.3 \mathrm{HV} 0.1$ and the bonding strength is about 27.0MPa.
\end{abstract}

\section{Introduction}

Magnesium alloys are being increasingly used in the automotive, aerospace and electronics industries for their excellent physical and mechanical properties, such as the low density, high stiffness, high strength to-weight ratio and mechanical castability[1-3]. However, because of the low wear resistance and high chemical reactivity of Mg alloys, surface treatment is normally required for $\mathrm{Mg}$ alloy in order to improve their surface durability. Different surface modification techniques have been developed and used to improve the corrosion resistance of magnesium alloy, such as chemical conversion [4], plating [5], micro-arc oxidation [6] and chemical vapour deposition [7]. However, due to the high chemical activity of magnesium in aqueous solutions, most of the existed surface modification techniques fail to offer sufficient protection for magnesium alloy components in their service environments.

As a relatively new surface treatment technique, cold spray (CS) has attracted more and more attention, by which coatings can be prepared without involving both feedstock and substrates into high temperature atmosphere. In the CS process, micro-particles are accelerated to supersonic velocities and being impacted onto a substrate surface, and the coating is formed by plastic deformation of sprayed particles in a solid state during impact in cold spraying. The temperature of sprayed particles prior to impact is much lower than their melting points and sprayed materials experience little microstructure change, oxidation or decomposition [8]. Most metals including $\mathrm{Cu}$, $\mathrm{Al}$ and their alloys can be deposited by cold spraying [8-9], and even cermets [8]or ceramic particles [9]can be embedded into a metal substrate to form a thin layer coating. The bonding of particles in cold spraying is presumed to be the result of extensive plastic deformation and related phenomena at the interface. The bonding mechanisms in cold spraying can thus be compared to those in processes such as explosive cladding or shock wave powder compaction. These latter processes have been explored widely with respect to mechanisms of bonding as well as to possible applications [10].

This paper is to study microstructure and mechanical properties of cold spraying $\mathrm{Al}$ coating on AZ31 magnesium alloy.

\section{Experiment and results}

Commercially pure aluminum powder was used as spraying material. The particle size and shape were examined by scanning electron microscopy (SEM, JSM-5610LV). As shown in Fig. 1, the 
diameters of the spherical Al particles range from 1 to $40 \mu \mathrm{m}$. As-cast AZ31D magnesium alloy was used as substrate for cold spraying. the substrate was ground using sand paper down to 800 grit followed by acetone cleaning, then sandblasted using 24 mesh alumina grit just prior to deposition. The coating was deposited on the AZ31 substrate using a CS system developed in the laboratory, and Fig 2 shows the schematic drawing of CS system. The spraying standoff distance was maintained at $30 \mathrm{~mm}$ away from the nozzle exit. Compressed air was used as accelerating gas and carrier gas for powder feeding. During the spraying process, the accelerating gas was pre-heated to $350{ }^{\circ} \mathrm{C}$ with pressure of 1.6 MPa. Microhardness measurements were performed on mounted samples using a conventional Vickers hardness tester with a $100 \mathrm{~g}$ load and a dwell time of $15 \mathrm{~s}$.The adhesion of coating to substrate was measured using a Z-axis stud pull machine.

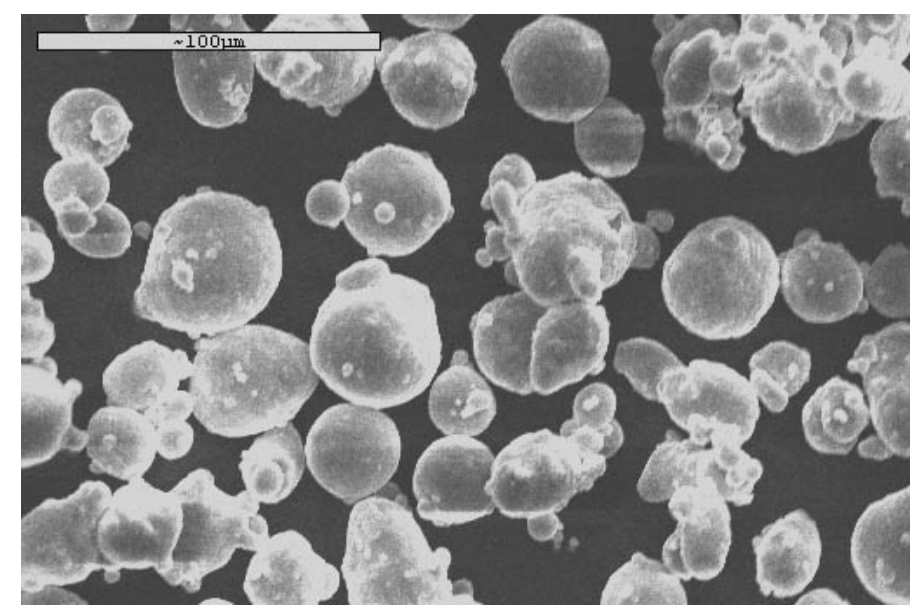

Fig 1 SEM image of aluminum powders

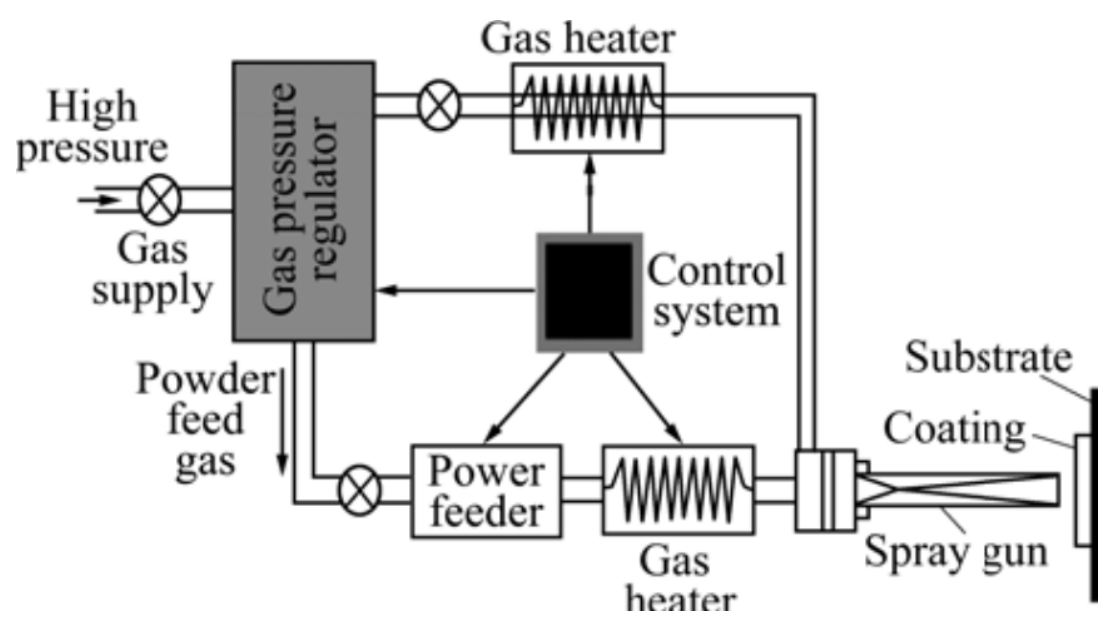

Fig 2 Schematic drawing of CS system

Fig 3 shows the plane and cross-sectional microstructure of cold spraying $\mathrm{Al}$ coating. It is found that $\mathrm{Al}$ particles are deformed significantly in the coating, and no spherical Al particles exit compared with original particles before spraying, which indicates that the particles are integrated to each other in the coating. There is no significant cracks along the interface between the coating and substrate, and it indicates that the coating is well bonded with the substrate. 

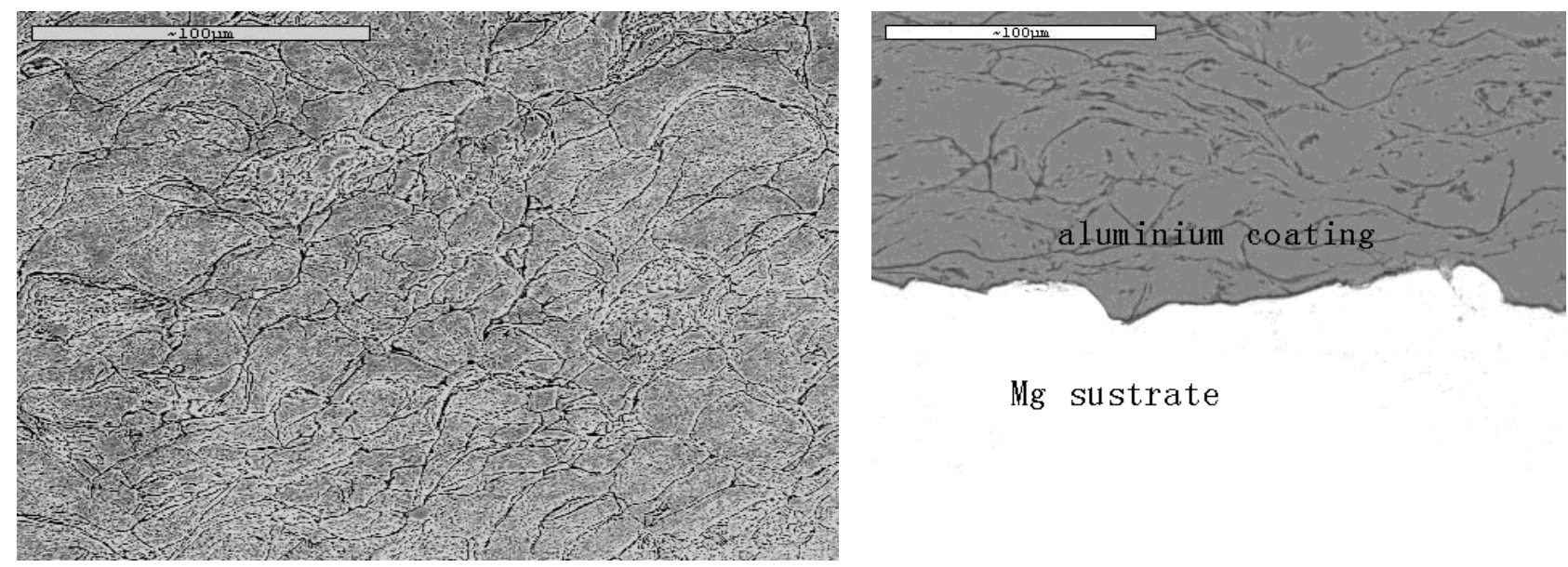

Mg sustrate

Fig $3 \mathrm{Al}$ coating microstructure (a) plane, (b) cross-sectional

Table 1 shows the microhardness of $\mathrm{Al}$ coating. Al particles are deformed during the coating formation process, while the particles are bonded mechanically and there are micro-pores in the coating, and that induces that microhardness of the coating is lower than that of bulk Al.

Table 2 shows the bonding strength of Al coating with substrate. During the tensile tests, the fracture occured in the interface between coating and substrate, and it indicates that the bonding strength of coating is higher than that of coating and substrate.

Tabl 1 Microhardness of Al coating

\begin{tabular}{|c|c|c|c|c|c|}
\hline \multicolumn{5}{|c|}{ Microhardness (HV0.1) } & \multirow{2}{*}{$\frac{\text { Average }}{178.3}$} \\
\hline 182.6 & 183.2 & 176.3 & 171.2 & 178.2 & \\
\hline \multicolumn{6}{|c|}{ Table 2 Bonding strength of Al coating } \\
\hline \multicolumn{5}{|c|}{ Bonding strength (MPa) } & Average \\
\hline 25.9 & 28.7 & 27.5 & 26.3 & 26.6 & 27.0 \\
\hline
\end{tabular}

\section{Conclusions}

Al coating is formed on AZ31 magnesium alloy by cold spraying. Al particles are deformed significantly in the coating, and the coating is well bonded to the substrate. Microhardness of the coating is about 178.3 HV0.1, and its bonding strength is about 27.0 MPa.

\section{Acknowledgments}

Financial support from the National Natural Science Foundation of China (NSFC - Henan Joint Fund of Personnel Training, U1404501) and Doctoral Foundation of Henan University of Science and Technology are acknowledged.

\section{References}

[1] G.L. Song, A. Atrens, Adv. Eng. Mater. 1 (1999) p.11

[2] G.L. Makar, J. Kruger, Int. Mater. Rev. 38 (1993) p.138

[3] F.H. Froes, Mat. Sci. Eng. A Struct. 184 (1994) p.119

[4] A.R. Shashikala, R. Umarani, S.M. Mayanna, A.K. Sharma, Int. J. Electrochem. Sci. 3

(2008) p.993

[5] J.F. Zhang, C.W. Yan, F.H. Wang, Appl. Surf. Sci. 255 (2009) p.4926 
[6] H.F. Guo, M.Z. An, Thin Solid Films 500 (2006) p.186 [7] T. Ishizaki, J. Hieda, N. Saito, N. Saito, O. Takai, Electrochim. Acta 55 (2010) p.7094

[8] C Borchers, F Gartner, T Stoltenhoff, H Assadi, H Kreye, J Appl Phys. 93 (2003), p. 10064

[9] RS Lima, J Karthikeyan, CM Kay, J Lindemann, CC Berndt, Thin Solid Films 416 (2002) p. 129

[10] Brasher DG, Butler DJ. Adv Mater Process, 147(1995), p. 37 